\title{
Bioética do cuidado na clínica de ensino: aprendendo com pacientes
}

\author{
Luísa Lapenta Cunha*; Fabiana Schneider Pires**; Mirelle Finkler***; Cristine Maria Warmling** \\ * Graduanda, Faculdade de Odontologia da UFRGS \\ ** Professora Doutora, Departamento de Odontologia \\ Preventiva e Social, Faculdade de Odontologia da UFRGS \\ *** Professora Associada, Departamento de Odontologia, \\ UFSC
}

Recebido: 29/10/2020. Aprovado: 15/03/2021.

\begin{abstract}
RESUMO
O estudo buscou compreender práticas de acolhimento de pacientes em uma clínica de ensino odontológico. Trata-se de um estudo de caso único e holístico, com abordagem qualitativa. Foram realizadas entrevistas abertas com 20 pacientes, guiadas por um roteiro com temas problematizadores que procuram ligar princípios bioéticos a dispositivos subjetivos do cuidado: conceito ampliado de saúde e doença, intersubjetividade, corresponsabilidade e qualidade de vida. As práticas discursivas analisadas mostraram que o vínculo entre estudantes e pacientes da clínica de ensino se estabelece em uma construção mediada pelo longo tempo da formação. A corresponsabilidade está relacionada às construções intersubjetivas no cuidado e tem como atores do processo os estudantes e os pacientes. Ao afirmarem sentirem-se livres para opinar sobre seus tratamento também expressam uma postura de reduzida autonomia, pois consideram que não seja necessário fazê-lo. Como reflexo da fragmentação do cuidado nas clínicas de ensino, muitos silenciamentos emergem destas relações de poder e cuidado. Acredita-se que é clara a importância de práticas que se desvinculem de funções estritamente técnicas e invistam nos processos de fala e escuta, incansavelmente buscando empatia e vínculo como as tecnologias de saúde mais potentes para o tratamento, pois reafirmam a autonomia das pessoas na construção de seus itinerários de cuidado e a dignidade humana como valor central da prática de saúde.
\end{abstract}

Descritores: Bioética. Análise Ética. Acolhimento. Educação em Odontologia.

\section{INTRODUÇÃO}

Em que medida o cuidado ao paciente em uma clínica de ensino odontológico está fundamentado em construções bioéticas? A clínica de ensino odontológico se pauta no acolhimento, no reconhecimento das condições de vida, no desenvolvimento de processos de intersubjetividade, de autonomia e de 
corresponsabilização do paciente? Ou se mantém alicerçada nas relações hierárquicas do tipo paternalistas, com um espaço mínimo de participação e autonomia das pessoas assistidas, desconsiderando-se conflitos éticos e priorizando as necessidades de aprendizado sobre as de cuidado do paciente?

O campo de estudos da bioética está fundamentado na crítica ao enfrentamento do adoecimento por meio de arranjos extremamente tecnologizados que atuam em detrimento do paciente em seu contexto pessoal, social e cultural. Em uma aproximação da Saúde Coletiva, a Bioética busca subverter o sentido tradicional de se compreender saúde e doença - do individual ao coletivo, da tecnificação à humanização. Por enfatizar a análise de valores presentes no modo como as pessoas se relacionam, a bioética aporta referenciais teórico-metodológicos para o processo de humanização na saúde ${ }^{1,2}$. Torna-se eixo central para a compreensão da dignidade do viver e da valorização da vida enquanto aspectos fundamentais, pois evidencia os benefícios da ciência em equilíbrio com a humanização, superando práticas de saúde arraigadas aos aspectos tecno-científicos e não ao vínculo com o paciente ${ }^{3}$, com a sociedade e com o meio ambiente.

$\mathrm{O}$ agir profissional orientado por práticas bioéticas é construído transversalmente no percurso de formação de futuros profissionais de saúde. Como estruturante da educação superior na saúde, a compreensão do papel da bioética na produção do cuidado em saúde é um desafio no atual contexto de medicalização da vida. O ensino da ética e da bioética nos percursos de graduação em saúde inclui o processo de formação de profissionais para realizar o cuidado na saúde, problematizando as intervenções profissionais em um caminho de reconhecimento dos direitos dos pacientes. Quando a formação atribui à educação bioética menor valor, negligencia a humanização de futuros profissionais responsáveis por assistir à população, que irá receber técnica sem solidariedade, assistência sem empatia e terapêutica sem cuidado ${ }^{4}$.

O distanciamento entre as disciplinas do campo das Ciências Sociais e Humanas das do eixo profissionalizante, somado ao modelo da clínica de ensino, podem provocar situações de redução da liberdade de fala do paciente e consequentemente de sua autonomia e da corresponsabilidade terapêutica.

Nas práticas de cuidado na saúde o acolhimento é uma atitude que oportuniza o encontro qualificado entre profissional e paciente/família. É espaço para escuta bioética, nem sempre centralizada nos problemas de saúde, mas no mútuo reconhecimento de direitos e deveres no processo de tomada de decisões clínicas eticamente fundamentadas. A acolhida, no processo de cuidado, é concebida como a corresponsabilização das demandas de uma comunidade ou de uma pessoa, quando se incorpora nas decisões a subjetividade das diferenças $^{5}$. O resgate de valores de solidariedade, cidadania e respeito com o paciente resultarão na promoção da autonomia e na corresponsabilização com seu tratamento ${ }^{6}$. Tanto o acolhimento como o vínculo se encontram associados aos conceitos de intersubjetividade e humanização. A produção de vínculo com os pacientes amplifica a atenção à saúde e favorece a participação durante o cuidado. $\mathrm{O}$ vínculo com o paciente está relacionado ao seu reconhecimento como participante no processo de decisão ${ }^{7}$.

Partindo-se destes pressupostos, o estudo buscou compreender o modo como são colocados em correlação princípios bioéticos e conceitos de cuidado e acolhimento na clínica de ensino odontológico. Por meio do estudo das práticas discursivas de pacientes em atendimento procurou-se analisar como os estudantes de Odontologia têm desenvolvido processos de acolhimento no atendimento na clínica de ensino. 


\section{METODOLOGIA}

Trata-se de um estudo de caso $^{8}$ do campo da educação e da saúde. A abordagem do estudo foi qualitativa.

O curso de Odontologia, objeto do estudo, estruturou seu projeto pedagógico ${ }^{9}$ adequando-se às Diretrizes Curriculares Nacionais vigentes ${ }^{10}$, em busca de um perfil profissiográfico que articule o processo de ensino-aprendizagem por meio da aquisição de competências e de habilidades. Contempla em seu currículo uma combinação de disciplinas básicas, clínicas de ensino e estágios curriculares. A matriz curricular está voltada para aproximar a formação profissional aos serviços e o envolvimento com a rede de serviços deve ocorrer já no primeiro semestre do curso, este comprometimento é gradativo, sendo que o maior número de créditos planejados se dá nos dois últimos semestres quando os estágios são desenvolvidos como principal atividade formativa discente ${ }^{11}$.

No currículo do curso de graduação em Odontologia que foi cenário deste estudo, as clínicas de ensino estão organizadas com o objetivo de integrar ensino e assistência no âmbito das especialidades odontológicas. Os professores (tutores) acompanham os procedimentos realizados pelos estudantes no transcorrer da clínica, havendo metas de procedimentos odontológicos como critérios avaliativos do ensino-aprendizado dos estudantes.

Participaram da pesquisa 20 pacientes ou responsáveis por menores em atendimento nas clínicas desta instituição de ensino pública do sul do país, sendo $75 \%$ mulheres, $40 \%$ possuíam 60 anos ou mais, $45 \%$ eram casados e $80 \%$ residiam em [texto ocultado] e na região metropolitana.

Utilizou-se da entrevista para a produção de dados a partir de um roteiro norteador, correlacionando temas dos processos de acolhimento no cuidado com princípios bioéticos: conceito ampliado de saúde e doença - critério de justiça; intersubjetividade e corresponsabilidade - critério de autonomia; e qualidade de vida -critério de beneficência e não-maleficência (quadro 1).

Quadro 1. Roteiro da entrevista aberta fundamentado nas temáticas de análise pré-definidas

\section{Conceito ampliado de saúde e doença:}

Como você acha que é o conhecimento do estudante que lhe atendeu sobre a realidade de suas condições de vida, saúde e doença? Fale sobre isso.

Intersubjetividade:

Considerando as consultas para a realização do seu tratamento, como se estabeleceu a sua relação com o estudante? Conte como é sua relação com ele.

\section{Autonomia:}

Sobre o percurso do tratamento: quanto de liberdade você teve para decidir ou opinar? Fale sobre isso. Como as suas decisões e opiniões foram respeitadas ou não.

\section{Corresponsabilidade:}

De que modo você participou no tratamento e nas consultas? Fale sobre isso.

Qual foi a sua contribuição no tratamento?

\section{Qualidade de vida:}

Como você avalia o tratamento (a decisão das escolhas técnicas) que recebeu? Fale sobre possíveis problemas (dor/desconforto/limitação da vida)? 
Os participantes foram convidados para a entrevista enquanto esperavam por atendimento ou haviam terminado o atendimento, nos ambientes de espera das clínicas de ensino. As entrevistas duraram em média 40 minutos. Posteriormente foram transcritas para análise. A saturação - o reconhecimento de que os dados colhidos são suficientes para explicarem o problema, foi adotada como critério de avaliação para definição do momento de interromper a coleta de novos dados ${ }^{12}$.

A metodologia de análise das práticas discursivas realizada procurou situar-se na compreensão das relações históricas, sociais e culturais presentes nas práticas vivas do modo como os discursos se apresentam. Os sentidos dos objetos em estudo não são traduzidos apenas pelas falas dos sujeitos, mas articulam o linguístico com o social e o histórico. A linguagem é produção política e constitutiva das próprias práticas e não a simples referência ou expressão das situações. Identificaram-se as regularidades intrínsecas das redes conceituais presentes nas práticas discursivas, delimitando conjuntos de enunciados que apoiam formações discursivas ${ }^{13,14}$.

O projeto de pesquisa foi submetido para análise ética no Comitê de Ética em Pesquisa institucional e está na Plataforma Brasil sob o CAAE 30459914.8.00005347 com parecer número 2.522.074. Aos convidados foi apresentado o Termo de Consentimento Livre e Esclarecido, tendo sido considerados participantes da pesquisa as pessoas que concordaram em assiná-lo.

\section{RESULTADOS E DISCUSSÃO}

\section{Do conceito ampliado de saúde e doença à clínica nas práticas do cuidado}

Na clínica de ensino odontológico do estudo, a anamnese e o exame físico compõem o protocolo de abertura para início do atendimento odontológico dos pacientes. O prontuário adotado pelas clínicas de ensino possui espaço de perguntas para que se identifique e se descreva dados sociais do paciente. Entretanto, nas práticas discursivas analisadas, os pacientes entrevistados relatam sua primeira consulta odontológica na clínica de ensino como um momento no qual são feitas perguntas gerais sobre sua saúde, porém na forma de uma entrevista desarticulada do processo de cuidado e de intervenções clínicas. De acordo com as respostas dos participantes, os estudantes estabelecem frágeis relações entre o universo dos pacientes (aspectos culturais, sociais, crenças, entre outros), seus processos de adoecimento e a produção do cuidado.

Eles fazem uma pesquisa quanto a saúde. Perguntam sobre doenças e medicações. Eu já passei por vários e todos fazem a mesma coisa [...] quanto a minha vida pessoal não sabem nada (E11).

Quando eu chego aqui eles me fazem mil perguntas para saber exatamente o que eu tenho. Eu acho que eles até estão bem informados [...] (E03).

Acho que todos sempre fazem aquelas mesmas perguntas sobre doença, né? Que inclusive eu tenho problema mesmo, mas, eu acho que eles não têm muito interesse, é mais por fazer mesmo [...] (E04).

Quanto à saúde como um todo não sei se sabe muito, eles fazem aquelas perguntas só. Agora quanto a saúde bucal acho que sabe tudo (E12).

Para mim nunca perguntaram nada sobre minha saúde, sobre doença nenhuma, nada. Sempre falaram só de dente (E14).

A saúde e o adoecer são formas pelas quais a vida se manifesta. $\mathrm{O}$ conceito ampliado de saúde, preconizado na legislação que fundamenta o Sistema Único de Saúde (SUS), reconhece que sua dimensão biológica está integrada às dimensões política e social. No modelo biomédico ainda hegemônico, há uma redução do corpo humano, ao focar a dimensão biológica, desconectando-o do 
conjunto de relações culturais e dos contextos concretos da vida social. Atitudes redutoras da compreensão dos modos de vida e do adoecimento culminam em comportamentos limitantes das potências do cuidado.

Na sua produção, o processo saúde-doença é compreendido como articulado aos modos de viver de cada pessoa - suas relações pessoais históricas buscando contemplar as singularidades da produção da vida. É a habilidade da acolhida a quem procura por cuidado que permite o compartilhamento ou não de informações pessoais $^{6,15,16}$. A vida se produz no cotidiano das relações sociais, familiares e de trabalho. Muitas vezes, este é um fato desconsiderado no espaço de ensino-aprendizado da clínica, quando a saúde é tratada como um atributo definido exclusivamente a partir das condições de normalidade e anormalidade psicobiológicas estabelecidas pela Biomedicina $^{17}$.

As práticas discursivas demonstram que os estudantes dominam os conhecimentos técnicos e científicos valorizados pelos modelos biomédicos de atenção, também necessários para o cuidado. No entanto, os pacientes não compreendem o modo como o conhecimento do estudante sobre aspectos pessoais e sociais da sua vida pode se relacionar à construção de percursos terapêuticos na clínica de ensino

$O$ conhecimento é especifico, o tratamento é específico, então não tem por que saber da minha vida, minha família (E14).

Acho que ela não sabe muito sobre a minha vida, de repente com tempo isso vai aumentando. Acho que não influencia ela saber isso. O tratamento é igual para todos, seja rico ou seja pobre, tem que ser tudo igual (E09).

Acho que esse conhecimento mais intimo vai de cada pessoa, querer saber da vida do paciente. Comigo nunca fizeram grandes perguntas nesse sentido, mas com certeza é importante porque tem que saber o contexto em que o paciente vive, coisas subjetivas (E16).

Ah, eu acho muito importante partilhar informações pessoais, conversar mesmo. Até porque quando duas pessoas não se dão, aí fica difícil (E18).

Acho que ter esse conhecimento quanto a vida pessoal acrescenta muito. Tu poder interagir como paciente, cria afinidade. Acho muito positivo, muito importante. Aquele que te atende só profissionalmente faz com que tu te retraia e até não fale certas coisas. Eu acho que quanto maior a abertura, melhor a comunicação, melhor o tratamento (E11).

Os processos históricos de constituição do ensino da saúde podem ajudar a explicar as dificuldades dos estudantes em aproximar conhecimentos sobre contextos sociais do paciente à produção de cuidado nas atividades clínicas que realizam. A clínica odontológica, em seu processo histórico, se confundiu (e se confunde ainda hoje) com a técnica odontológica, tanto nas práticas profissionais como no ensino. O ensino (e a prática) odontológicos consolidou sua organização e regulamentação por meio da separação da medicina ${ }^{18}$.

O ensino odontológico é um protagonista na tecnificação da profisssão ao dissociar a clínica e o cuidado das condições de existência e da vida das pessoas. Com um centramento no dentário e cercando-se de narrativas circunscritas à superfície da coroa do dente, a prática profissional tem sido desenhada, modelada e confere cientificidade aos discursos dentários - uma das funções da disciplina - e estabelece a rede de interesses que vincula escola, profissão e indústria na educação do cirurgião-dentista ${ }^{19}$.

Um olhar bioético para o trabalho em saúde traz para o foco do debate questões sobre o cuidado, 
procurando superar abordagens higienistas $\mathrm{e}$ prescritivas, centradas na doença e na produção de procedimentos, por compreensões mais humanísticas, centradas nas pessoas, nas relações intersubjetivas e na determinação social da saúde. No conceito de território existencial, situacional e portador de muitos sentidos, o paciente é corresponsável pela construção de sua rede de cuidado. Nesse contexto, a construção e o fortalecimento dos vínculos existenciais e terapêuticos constituem-se como ferramentas para as práticas de cuidado ${ }^{20}$.

As práticas discursivas analisadas problematizam a clínica de formação profissional na Odontologia. Como um estudante produz e usa informações sobre saúde e doença do paciente na clínica e de que modo constrói o cuidado?

\section{Intersubjetividades: possibilidades de} produção de acolhimento na clínica de ensino

As práticas discursivas indicam que os estudantes são reconhecidos tanto pelas práticas técnicas como pelas características pessoais. As práticas de interação entre os estudantes e os pacientes são mediadas por dispositivos informacionais, redes emocionais, habilidades sociais e, especialmente, práticas comunicativas.

[...]Essa relação vai acontecendo, primeiro pela maneira querida $e$ interessada deles. Eles não me olham como seu eu fosse apenas uma pessoa que está ali para que eles possam executar o trabalho. Sempre tive muita sorte! Eu sei de detalhes da vida deles como eles sabem da minha e isso tem só a acrescentar no tratamento (E11).

Criei um relacionamento com certeza. Eu sempre fui muito bem atendida e a gente acaba criando um vínculo. Foi se formando o vínculo aos poucos, foi se tendo mais intimidade. A aluna sempre foi muito aberta, muito simpática e isso colaborou bastante (E07).

É uma relação bem boa, tenho o contato de WhatsApp dela. Ela sempre se coloca à disposição para qualquer esclarecimento que eu precise e me avisam também, se eu peço pra ela algo ou eu não venho. Qualquer esclarecimento que precise. Isso é muito bom! (E12).

As subjetividades com relação ao tema da saúde bucal expressadas nos pacientes estão ligadas com as suas próprias vivências odontológicas, como resultantes de produções de relações de poder, não apenas compreendidas como opressões ou dominações, mas, principalmente, no seus processos de construção, pois que resultam de uma objetivação, que transforma o ser humano em um sujeito produtivo $^{13}$. A subjetividade é portanto aqui compreendida um recurso de poder no ato do cuidado: um biopoder, ou seja, um poder sobre o corpo. E o sujeito é, ao final, um produto desses processos chamados de biopolíticos ${ }^{3,21}$.

A intersubjetividade é mais do que compreensão compartilhada ou mútua, pois está mais próxima da noção da possibilidade de estar no lugar onde o outro está. Além disso, a intersubjetividade não é necessariamente algo a ser alcançado ou negociado por meio da comunicação verbal ou outros meios. Aspectos humanos e não humanos dos ambientes de saúde conduzem os processos de intersubjetividade entre profissional e paciente, mediados pelas tecnologias de saúde. Nessa visão, a intersubjetividade é, em primeiro lugar, não um produto ou efeito da comunicação, mas uma condição para sua possibilidade ${ }^{22}$.

$\mathrm{O}$ atendimento na clínica de ensinoaprendizado transcorre ao longo dos semestres letivos com uma dinâmica singular e complexa. Torna-se um tempo maior, considerando habilidades, necessidades de supervisão constante e a própria evolução do aluno no percurso curricular, o que atrasa a conclusão dos 
tratamentos. Estudantes em formação não apresentam a agilidade e destreza de profissionais com experiência e dependem da presença de professores para aprovação das etapas dos procedimentos.

[...] tempo aqui não existe. É tudo muito demorado. A pessoa tem que entrar sabendo que vai ser demorado o tratamento, como eu entrei. Se a pessoa não entra sabendo acho que vai ficar meio irritada com a demora (E07).

[...] Tem muita gente e o professor acaba não conseguindo dar a devida atenção pra todos, têm pouco tempo. Acho que se eles ficassem mais com os alunos os tratamentos não se durariam tanto tempo. Essa é a minha ressalva, pois foi isso que aconteceu comigo (E11).

[...] uma coisa que demora muito, é o tratamento para se fazer um provisório, eu estou com um provisório a quase um ano, não é possível, né? (E04).

Para conseguir a vaga até foi bem rápido, mas agora eu já to aqui tem mais de um ano e acho que ainda vai bem mais longe (E12).

Os pacientes são atendidos por diferentes estudantes, o funcionamento da clínica de ensino segue o fluxo semestral de evolução dos estudantes no currículo, com mudanças nas equipes de docentes e estudantes, e obrigatoriedade de términos e reinícios de tratamentos. Também os níveis de complexidade das clínicas estão organizados no desenvolvimento curricular semestral. Infelizmente, os pacientes com necessidades de saúde que envolvam procedimentos de maior complexidade passam em diferentes clínicas (clínica infanto-juvenil, clínica I, II, III e IV, clínicas de extensão, clínicas de especialização, para exemplificar) e são atendidos por diferentes estudantes e professores. Um processo que pode conferir fragilidades na comunicação e vínculo com os pacientes. Nesse contexto, um dado apresentado pelo estudo e que merece ser avaliado é que em torno de $30 \%$ dos entrevistados não identifica em qual clínica de ensino recebia o atendimento que estava sendo prestado.

Já teve muitos alunos que me atenderam, uns tempos são uns depois muda, mas todos sempre foram muito atenciosos (E01).

Os alunos mudam todos os anos. É uma dupla a cada seis meses. Nós já estamos acostumados com esse processo, mas todas as meninas que atenderam ele sempre foram muito queridas e preocupadas (E17).

Essas (im)possibilidades definem a produção do cuidado. Acolher as demandas e necessidades do paciente pressupõe reconhecer as condições do paciente para gerar informação sobre propostas de tratamento e autonomia de decisão. Na atenção à saúde, o acolhimento depende da intersubjetividade. Quando esse processo está degradado formam-se zonas de silenciamento ${ }^{23}$. Acolher proporciona interação entre profissional e paciente, oportuniza interpretação de singularidades e construção de relações. Acolhimento e vínculo são conceitos que se complementam na construção do cuidado. $\mathrm{O}$ acolhimento é oportunizador da formação de vínculo. A intersubjetividade produz comunicação com o outro e formação de vínculo ${ }^{2,6,24,25}$.

\section{Da autonomia à corresponsabilidade: a clínica como produtora de silenciamentos}

As práticas discursivas sobre liberdade de se expressar no transcorrer do tratamento clínico se apresentam em um intricado de variações, e até contradições, de como se materializa o opinar na clínica e no tratamento. Os participantes referem que não possuem liberdade para tal, ou se dizem livres, mas não julgam necessário fazê-lo, por avaliarem que não possuem conhecimentos 
suficientes e confiarem nas decisões dos estudantes e professores. Nesse sentido, os pacientes entrevistados encontram um 'lugar' neste processo e se mantém-se distanciados do seu tratamento e cuidado.

\section{[...] Acho que não tinha completa} liberdade, pois não me passaram as informações completas para que eu tomasse minhas decisões [...] (E11). Não me senti livre, pois eu não tinha entendimento do caso. Ninguém me explicou tudo "tintin por tintin" para que eu tivesse escolha [...] (E20).

Tenho liberdade, mas procuro não opinar, já que eles sabem o que estão fazendo, mas me perguntam só que eu sempre deixo por eles. Acho que não é necessário (E03).

Eu tinha total liberdade se quisesse falar alguma coisa, mas nunca precisei. Caso fosse necessário eu iria expor minha opinião (E19).

[...] Eu não sei nada sobre isso então eu não tenho o direito de opinar. Eu posso perguntar mas opinar não. Eu já fiz comentário, mas não dei opinião. Até por que tem professor, né? Opinar só pro professor (E06).

Se eu senti abertura pra isso? Acho que sim. Mas é que a gente também não é dentista, então tem coisas que eu não posso falar porque eu não entendo direito. Mas não tive o que falar, acho que tá tudo bem. Mas com certeza eu me manifestaria (E12). Não, eu não sou assim, eu acho que ele ta fazendo o serviço dele e tudo bem, eu não vou falar e atrapalhar também. Ele está concentrado em alguma coisa.[...] Tem que ser profissional [...] (E14).

Eles fazem tudo certinho eu não preciso fazer nada [...] (E01).

A ideia da confiança profissional, que emergiu nas práticas discursivas analisadas, pressupõe um modelo de autoridade terapêutica, inclusive (ou principalmente) moral. Os participantes não exercem, pelo menos abertamente, o poder de escolhas quanto aos tratamentos. Como se o conhecimento profissional se sobrepusesse à liberdade da escolha dos sujeitos, reduzidos a coadjuvantes em um processo onde a figura central do cuidado não é o paciente. Suas opiniões são consideradas menos importantes do que os conhecimentos técnico-científicos. Cooperar consiste em seguir orientações, não faltar consultas e responder com exatidão perguntas colaborando com a formação do estudante.

Eu estou tentando fazer tudo o que ele me pediu: escovando melhor, comendo menos doce. Eu tenho um filho de 29 anos e ele incentiva muito e eu também estou passando a informação pra todo mundo. Eu entendi e aceitei tudo que o [estudante] me disse. Não é por que eu estou com 70 anos que eu não vou entender que está errado (E05).

A minha contribuição foi fazer em casa tudo certinho e nunca ter faltado as consultas, justamente por causa da demora (E07).

Minha parte foi sempre me organizar para vir aqui nas consultas e dar tudo certo. Eu sempre conversei com ela quando precisei mudar horário e ela sempre entendeu [...] (E10).

[...] mas eu colaborei bastante com ele. Ele fez coisas na minha boca que ele nunca tinha feito (E06).

Os pacientes, não querem, ou não podem importunar as acertadas decisões técnicocientíficas proferidas por professores e repetidas por estudantes, sob risco de perderem a possibilidade, ou a vaga, de tratamento. $O$ paciente se constrói em passividade para consumir a terapia que lhe será apresentada. É tomado como objeto de aprendizagem, como um corpo silenciado, 
apartado de suas concepções de saúde, de suas falas e desejos, que negligencia a si mesmo.

No campo epistemológico da Saúde Coletiva, um dos elementos básicos do conceito de promoção de saúde é encorajar e fortalecer a autonomia dos sujeitos ${ }^{26}$, com uma valorização do princípio bioético que promove o direito da pessoa decidir sobre as questões relativas a sua vida. Promover a corresponsabilização do cuidado da saúde dos pacientes é priorizar o direito do paciente à autonomia.

No código deontológico da profissão, do princípio da autonomia decorre o dever profissional de fornecer informações necessárias para a tomada de decisão prudente. Constitui infração ética não esclarecer propósitos, riscos, custos e alternativas de tratamento, ou "deixar de manter os usuários informados sobre os recursos disponíveis para o atendimento e de responder às reclamações dos mesmos"27.

A corresponsabilização em saúde é um exercício de poder sobre atitudes e decisões frente às possibilidades terapêuticas. Este exercício se relaciona com a capacidade de tomar atitudes ampliadas de saúde. Um exercício ligado aos processos pelos quais as pessoas dominam decisões e ações que afetam sua saúde e fortalecem a construção das próprias capacidades de escolha ${ }^{26}$. Corresponsabilidade define sujeitos que assumem um papel de protagonistas nos seus processos de saúde .

Quando alguém se propõe a analisar uma prática discursiva deve compreender o silêncio que acompanha as palavras. Mas, como analisá-lo? De que modo o não dizer se apresenta no dia-a-dia das práticas de saúde? O silenciamento é uma representação de relações de poder. Em toda a fala, em todo o encontro humano, há elementos nãoditos que podem ser nomeados como silenciamentos $^{28}$.

O silêncio torna toda significação possível, identifica o dizer que implica em não dizer. É o não se expressar devido a alguma conjuntura. A censura se apresenta no que não pode ser dito devido a intervenção de relações de forças no momento da enunciação ${ }^{28}$.

A pessoa que não comunica o que precisa comunicar, silencia. Um silêncio que se produz, para não expressar, não prejudicar. Foge-se de questionamentos, responde-se sem aprofundamento. $\mathrm{O}$ silêncio pode parecer ser de fácil identificação, contudo é de interpretação complexa, visto que explora dimensões do humano que são produzidas nas interfaces das práticas de cuidado da clínica de ensino.

Na teoria crítica, a "cultura do silêncio" não pode ser compreendida fora do contexto da situação analisada. Para que seja possível compreender a "cultura do silêncio" é essencial promover uma análise de como a sujeição em uma relação pode gerar diferentes formas de pensar, falar e fazer. "Ser silencioso não é não ter uma palavra autêntica, mas seguir as prescrições daqueles que falam e impõem sua voz" 29 .

De que modo estamos assujeitados às determinações das nossas próprias práticas e assujeitamos, nas intersubjetividades que produzimos e se produzem em nós, nossos modos de acolher no andar cotidiano de uma clínica de ensino - que até se propõe a ouvir, mas não consegue relacionar olhares entre o social e o clínico?

\section{Qualidade de vida: quem define critérios?}

Torna-se um exercício difícil usar o código de ética como fundamento em textos de análises bioética, tendo em vista que os códigos de ética são normativos e prescritivos e não fomentadores de uma problematização ética. E, o que se vê com certa frequência, é que a angústia gerada pelas situações de dúvida dos momentos de conflitos bioéticos leva a recorrer aos documentos deontológicos orientadores, abrindo-se mão da necessidade de refletir para tomar decisões em 
situações de incerteza. Um contexto que reforça questões deontológicas e diminui o espaço ou a visibilidade para a discussão bioética. Então, é estratégico mostrar que a deontologia precisa do aporte e aprofundamento das ciências sociais e humanas para crescer e ser analisada.

No caso do estudo, ao comparecer na clínica para realizar um tratamento de saúde (clínica esta que é também uma instituição de ensino), os pacientes trazem consigo demandas (mais ou menos explícitas), seu corpo e sua singular subjetividade. A relação clínica se constitui em um encontro de pessoas com interesses e subjetividades em produção, e com um objeto em comum: o corpo do paciente, e no caso do estudo, a boca, ou, ainda mais especificamente os dentes.

A decisão de uma pessoa em procurar atendimento em saúde em uma instituição de ensino não concede o acesso irrestrito ao seu corpo. É infração ética no Código de Ética Odontológica utilizar-se do paciente e/ou do aluno de forma abusiva em aula ou pesquisa e ainda sobrepor o interesse da ciência ao da pessoa humana ${ }^{27}$.

O profissional da saúde deve atuar em benefício da pessoa e possibilitar meios de conforto e bem-estar. A qualidade de vida do paciente está baseada na conciliação das suas preferências com as indicações clínicas $^{30}$. Está relacionada aos princípios bioéticos da beneficência e da nãomaleficência, que se complementam, com decisões que podem afetar a qualidade de vida do paciente. O Código de Ética Odontológica determina como dever fundamental do profissional, o zelo pela saúde e dignidade do paciente ${ }^{27}$. Contudo, como determinar a qualidade de vida? Estaria a indicação profissional provocando o bem, como preconiza o princípio da beneficência, quando se distancia do que a pessoa compreende por se sentir bem?

As decisões em um processo terapêutico devem estar fundamentadas não apenas nos objetivos profissionais e em suas indicações terapêuticas cientificamente fundamentadas, mas também no investimento afetivo, nas possibilidades cotidianas e modos de vida singular dos pacientes, aproximando a terapêutica das realidades pessoais e subjetivas. Os benefícios e malefícios devem ser confrontados com o ideal de qualidade de vida da pessoa atendida. Afinal, irá a pessoa aderir a um tratamento que não acredita?

Nas práticas discursivas analisadas, são compreendidas como acertadas pelos pacientes as decisões tomadas no percurso de tratamento.

O tratamento foi muito bom desde sempre. Sempre foram feitas as escolhas certas. Eu não tenho nada a reclamar. Ela sempre me deixou bem esclarecida, sempre estive a par de tudo. Nunca me senti mal em nenhum momento, essa anestesia aqui é muito boa, antigamente eu sentia muita dor (E10).

É a dor - passageira, crônica, momentânea, clínica, pós-operatória, que afeta a qualidade de vida do paciente odontológico. Quando a prática profissional atua no alívio da dor, o tratamento é entendido como uma recompensa a um esforço pessoal ou mais passível de ser suportado.

Quando eu fiz implante eu estava com medo, achei que eu ia morrer, nunca tinha feito na vida e eu sou fraca pra dor, mas fui orientada, tomei a medicação, fiz o bochecho e logo passou, fiquei numa boa (E02).

Eu já senti dor mas foi só na época da cirurgia, dai eu passei um whats, ele me explicou tudo e me ajudou[...] (E06).

$E u$ já senti bastante dor quando fiz a cirurgia dos sisos, mas depois passou, foi rapidinho. Acho que todo mundo que tirou siso passou por isso (E20).

[...] Dói, é sofrido mas eu não vou desistir[...] Ah, tu não tem noção do como vale a pena. Eu sei que vou sentir dor na hora ou no outro dia, mas vai passar e minha boca vai tá melhor. Então, pra mim 
tá ótimo. Vou continuar! (E03).

Com relação ao acesso (ou a dificuldade dele) ao atendimento, a concorrência para obter o atendimento é grande e há longa espera para os serviços odontológicos oferecidos na clínica de ensino, considerados de baixo custo se comparados ao mercado privado odontológico.

[...] Eu pago cinco reais, moça. Eu não tenho como reclamar de nada! (E16).

Eu tinha vontade de arrumar os dentes só que eu nunca tive oportunidade, nunca tive dinheiro pra fazer isso e aqui eles tão fazendo então eu não posso dizer nada, só tenho a agradecer [...] (E12).

Eu procuro não opinar para não atrapalhar nada. [...] É que na minha realidade é muito difícil, então eu conseguir a vaga aqui pra mim foi um máximo. Eu conseguir entrar aqui e ser cuidada, ser tratada pra mim foi ótimo. Não abro mão. Falto o trabalho se for preciso mas não posso perder isso aqui [...] (E03).

Tem coisas que eu não gosto no sistema daqui da faculdade, mas são pontos que se tem que aceitar quando se paga cinco reais pela consulta (E20).

Essas são questões que podem afetar a qualidade de vida do paciente, que diante da valorização do acesso à vaga de atendimento reduzem o valor das próprias vontades e opiniões, talvez por considerarem como um favor e não como um direito.

\section{CONSIDERAÇÕES FINAIS}

Na clínica de ensino, os estudantes dominam conhecimentos técnico-científicos e produzem informações sobre condições de vida dos pacientes, mas não relacionam esses conhecimentos na construção de percursos terapêuticos.

Por conceber que não possuem conhecimentos suficientes para tal ou por confiar nas decisões dos estudantes e professores, os pacientes limitam suas participações no transcorrer do tratamento clínico, criando um distanciamento do processo do cuidado. Cooperar é entendido como ser paciente no seu sentido literal: seguir orientações, não faltar consultas e responder com exatidão perguntas, submetendo-se ao tempo de tratamento em função da necessidade de formação do estudante.

As clínicas de ensino odontológico estruturam-se por uma ordem hierarquizada e fundamentalmente ocupada em capacitar estudantes para uma prática profissional orientada para a excelência técnica e destreza manual nos procedimentos clínicos.

$\mathrm{O}$ estudo traz à tona as competências bioéticas de uma clínica de ensino. Os resultados apontam para uma formação que persiste em fortalecer a centralidade do fazer em odontologia na doença e em um paciente que participe não atuando no processo do cuidado. A compreensão da clínica enquanto microespaço produtor de subjetividades, como processo para sujeitos e não para doenças ou reparos funcionais e estéticos pode deslocar a prática histórica da Odontologia e criar espaço para sujeitos que produzem saúde, que exercem sua autonomia e corresponsabilidade, tornando o ato de cuidar uma expressão de valores e uma produção de vida.

Sobre silenciamentos, relações de poder e cuidado, há que se constituir práticas que se desvinculam de funções estritamente técnicas e invistam na produção intersubjetiva e nos processos de fala e escuta, incansavelmente buscando empatia e vínculo como as tecnologias de saúde mais potentes para o tratamento, pois reafirmam a autonomia das pessoas na construção de seus itinerários de cuidado e a dignidade humana como valor central da prática de saúde.

\section{ABSTRACT \\ Bioethics of the care in the teaching clinic:}




\section{learning with patients}

The study aimed to understand welcoming patients practices in a dentistry teaching clinic. It is a holistic single-case study with a qualitative approach. Twenty patients were interviewed following an open-ended script containing problematizing topics trying to connect bioethical principles to subjective devices of care: expanded concept of health and illness, intersubjectivity, co-responsibility, and quality of life. The discursive practices analyzed showed that the bond between students and patients of the teaching clinic is established in a construction mediated by the long training time. Co-responsibility is related with the intersubjective constructions in the care, being the actors of the process both the students and the patients. When claiming to feel free to give an opinion on their treatment, they also express a position of reduced autonomy, as they consider that it is not necessary to give it. As a reflection of the fragmentation of the care in the teaching clinics, much silencing emerges from these relations of power and care. It is believed that that the importance of practices that unlink themselves from strictly technical functions and invest in the speaking and listening processes is clear. In an untiring search for empathy and bond as the most powerful health technologies for the treatment, they reaffirm the autonomy of the people in the construction of their itineraries of care and human dignity as a core value of the practice of health.

Descriptors: Bioethics. Ethical Analysis. User Embracement. Education, Dental.

\section{AGRADECIMENTOS}

O estudo foi financiado pelo Conselho Nacional de Desenvolvimento Científico e Tecnológico (CNPq) - Edital da Chamada Universal MCTI/CNPq ${ }^{\circ}$ 01/2016 (termo de concessão $n^{\circ}$ 42430/2016-3).

\section{REFERÊNCIAS}

1. Diniz D, Guilhem D. O que é bioética? São Paulo: Brasiliense; 2002.

2. Cotta RMM, Reis RS, Campos AADO, Gomes AP, Antonio VE, Siqueira-Batista R. Debates atuais em humanização e saúde: quem somos nós? Ciênc Saúde Coletiva, 2013; 18:171-9.
3. Junges JR. Direito à saúde, biopoder e bioética. Interface Comum Saúde Educ. 2009; 13(29):285-95.

4. Finkler M, Negreiros DP. Formação $x$ Educação, Deontologia x Ética: repensando conceitos, reposicionando docentes. Rev ABENO 2018; 18(2): 37-44.

5. Warmling CM, Baldisserotto J, Rocha ET. Acolhimento \& acesso de necessidades de saúde bucal e o agir profissional na Atenção Primária à Saúde. Interface. 2019; 23:1-15.

6. Garuzi M, Achitti MCDO, Sato CA, Rocha SA, Spagnuolo RS. Acolhimento na Estratégia Saúde da Família: revisão integrativa. Rev Panam Salud Publica. 2014; 35:144-9.

7. Nora CRD, Junges JR. Política de humanização na atenção básica: revisão sistemática. Rev Saúde Públ 2013; 47(6):1186-200.

8. Yin, RK. Estudo de Caso: planejamentos e métodos. Porto Alegre: Bookman; 2015.

9. Universidade Federal do Rio Grande do Sul. Faculdade de Odontologia. Projeto Político Pedagógico. Porto Alegre; 2005. [Acesso em 16 jun. 2020]. Disponível em: http// www.ufrgs.br/odonto/projeto_político. pdf.

10. Ministério da Educação. Conselho Nacional de Educação. Câmara de Educação Superior. Resolução CNE-CES n. ${ }^{\circ}$ 3. 2002. Institui as Diretrizes Curriculares Nacionais do Curso de Graduação em Odontologia. Diário Oficial da União, Brasília, 4 mar. 2002. Seção 1, p. 10. [Acesso em: 02 jun 2020]. Disponível em: http://portal.mec.gov.br/cne/arquivos/pdf/CE S032002.pdf.

11. Universidade Federal do Rio Grande do Sul. Faculdade de Odontologia. Resumo do prósaúde faculdade de odontologia da Ufrgs 2009. [Acesso em: 02 jun 2020]. Disponível em: http://www.prosaude.org/odo/resumo /UFRGS_ODO.pdf.

12. Minayo MCS. Sampling and saturation in 
qualitative research: consensuses and controversies. Rev Pesqui Qualitat. 2017; 5(7): 01-12.

13. Fischer RMB. Foucault e a análise do discurso em educação. Cad Pesqui. 2001; 114:197-223.

14. Caregnato RCA, Mutti R. Pesquisa qualitativa: análise de discurso versus análise de conteúdo. Texto Contexto Enferm. 2006;14(4): 679-84.

15. Backes DS, Lunardi VL, Lunardi WDA. humanização hospitalar como expressão da ética. Rev Latinoam Enferm. 2006; 14(1):1325.

16. Martins AA, Franco TB, Merhy EE, Feuerwerker LCM. A produção do cuidado no Programa de Atenção Domiciliar de uma Cooperativa Médica. Physis. 2009; 19(2): 457-74.

17. Nogueira RP. Determinação Social da Saúde e Reforma Sanitária. Coleção Pensar em Saúde.Rio de Janeiro: CEBES; 2010.

18. Warmling CM, Schneider Pires F, Baldisserotto J, Levesque M. Ensino da bioética: avaliação de um objeto virtual de aprendizagem. Rev Bioét. 2016; 24(3): 50317.

19. Botazzo C. O conhecimento pelas mãos. Rev ABENO 2017; 17(4): 2-19.

20. Marques VRS. O acolhimento como vertente de humanização na atenção à saúde do homem. Rev Científ Inst Ideia 2019; 1(8): 191-9.

21. Lancetti A. Notas sobre humanização e biopoder. Interface Comun Saúde Educ. 2009; 13 (Suppl.1):797-9.

22. Ayres JRCM. Sujeito, intersubjetividade e práticas de saúde. Ciênc Saúde Colet. 2001; 6(1): 63-72.

23. Castiel LD. Dédalo e os Dédalos: identidade cultural, subjetividade e os riscos à saúde. In: Czeresnia D, Freitas CM. Editores. Promoção da Saúde: conceitos, reflexões, tendências. Rio de Janeiro: Fiocruz; 2009. p. 83-99.

24. Lopes GVDO, Menezes TMDO, Miranda AC, Araújo KLD, Guimarães ELP. Acolhimento: quando o usuário bate à porta. Rev Bras Enferm. 2014; 67(1): 104-10.

25. Vasconcelos FN, Vasconcelos EM, Duarte SJH. O acolhimento na perspectiva das Equipes de Saúde Bucal inseridas na Estratégia Saúde da Família: uma revisão bibliográfica da literatura brasileira. Tempus 2011; 5 (3): 115-22.

26. Czeresnia D. O Conceito de Saúde e a Diferença entre Prevenção e Promoção. In: Czeresnia D, Freitas CM. Editores. Promoção da Saúde: conceitos, reflexões, tendências. Rio de Janeiro: Fiocruz; 2009. p. 43-57.

27. Conselho Federal de Odontologia. Código de ética odontológica: Resolução $\mathrm{n}^{\circ} 118$ de 11 de maio de 2012. Rio de Janeiro, 2012. [Acesso em: 02 jun 2020]. Disponível em: http://www.cropr.org.br/uploads/arquivo/724 571448d7a83c915ebc18e218042a3.pdf.

28. Orlandi EP. As formas de silêncio: no movimento dos sentidos. Campinas: editora da UNICAMP; 1992.

29. Freire P. Conscientização: teoria e prática da libertação: uma introdução ao pensamento de Paulo Freire. São Paulo: Moraes; 1980.

30. Moreira LAC. Ética e aspectos psicossociais em crianças e adolescentes candidatos a cirurgia bariátrica. Bioética. 2017; 25(1): 10110 .

\section{Correspondência para:}

Fabiana Schneider Pires

e-mail: fabianaspires@gmail.com

Rua João Caetano, 79/901

90470-260 Porto Alegre/RS 